\section{A DOUBLE BARREL FOR PERFECT RESULTS}

GC G-CEM LinkAce is a dualcure self-adhesive universal resin cement delivered in double barrel automix syringe, designed for the adhesive luting of all-ceramic, metal or composite indirect restorations. Offering the highest polymerisation in self-cure mode, G-CEM LinkAce ensures perfect results, regardless of the type of prosthetic material that is being cemented. The proprietary phosphate monomers of G-CEM LinkAce guarantee an unsurpassed bonding durability. The high wear resistance and colour stability give peace of mind when luting CADCAM and metal-free restorations.

The advantages are:

- Highly efficient self-curing mode

- Excellent bonding property to all modern restorative materials

- High bond-strength to dentine and enamel in both self-cure and dual-cure modes

- No need for pre-conditioning on the tooth structure

- Fluoride release for additional security

- No post-operative sensitivity

- Excellent colour stability

- Lowest linear expansion

- Adequate radiopacity

- No need for refrigeration.

The indications are: cementation of all types of all ceramic, resin and metal-based inlays, onlays, crowns and bridges; and cementation of metal, ceramic, fibre posts, and cast post and cores.

For further information contact GC UK on 01908218999.

\section{INTUITIVE MAGNIFICATION, ADVANCED OPTICS}

A set of Carl Zeiss loupes offers advanced optics for improved visual acuity and quality of clinical treatment. Carl Zeiss offers a comprehensive variety of models, ranging from the EyeMag Pro to the lightweight GTX and TTL Teleloupe. Available exclusively from Nuview in the UK, Carl Zeiss' range of dental loupes offers impeccable visual enhancement aids that combine high quality optics with sophisticated design.

For high quality visualisations and colour fidelity that extends to peripheral zones, a set of Carl Zeiss loupes allows clinicians to treat patients with superior vision and an improved accuracy. Carl Zeiss loupes are fully adjustable, which allows clinicians to maintain the perfect working distance between them and their patient, decreasing the chances of a musculoskeletal disorders developing.

Carl Zeiss loupes guarantee comfort and precise visuals that improve posture and help clinicians to reduce the risk of eyestrain, as well as neck and back problems. Nuview is committed to ensuring that every customer receives a reliable set of dental loupes which is configured to suit their individual needs and requirements.

For more information call Nuview on 01453872266 , emailinfo@nuview-ltd.com or visit www.nuview.co.

\section{THE HIGH-EARNING MOUTHGUARD}

When you prescribe an Oralift appliance it will enable you to earn up to $£ 2,000$. Quick and easy to do, prescribing Oralift appliances offers a high return on your investment in time.

The Oralift device is designed to reduce and delay the signs of facial ageing (crow's feet, wrinkles, loss of skin tone, sagging jowls etc) without the need for surgery, needles or artificial fillers.

Oralift is a thermoplastic bite-guard which is easy to fit over the mandibular teeth similarly to a small mouthguard. It is worn for between 30 minutes and two hours, every third day for four months initially. After this, two month top-ups twice a year is all that is needed. Requiring no exercise programme, the facial muscles are simply activated to create the rejuvenating effect by just wearing it in the mouth. After a matter of weeks, patients will start to notice Oralift's rejuvenating effects, which can become stronger and more pronounced as they continue the therapy.

Oralift therapy is simple, easy to use and above all totally natural.

To learn more about the Practice Building Benefits of Oralift attend one of Nick Mohindra's Two Day Hands On Courses. The $£ 650$ course fee includes 12 hours' verifiable CPD and a free set of Oralift appliances. The next course will be held in London on 27-28 June 2014.

To book a place or for further information visit www.oralift.com oremailinfo@oralift.com.

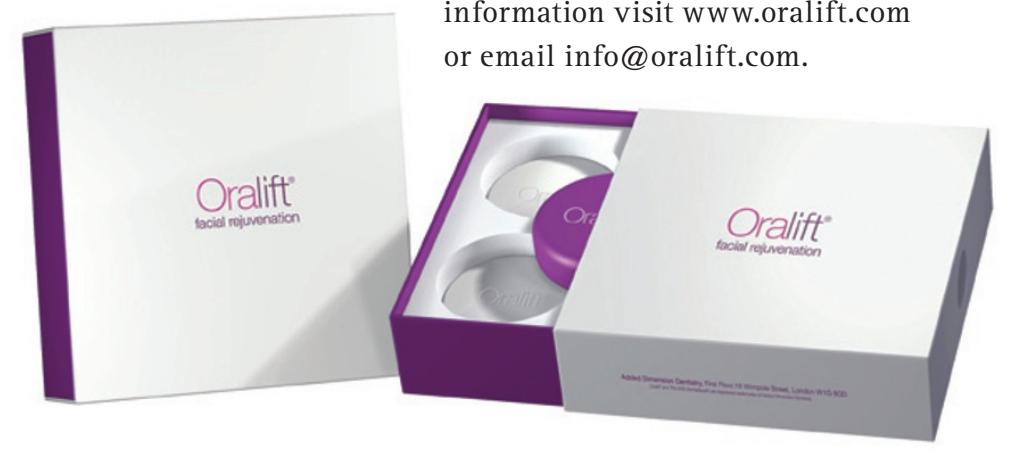

\section{DON'T GET LEFT BEHIND WITH TOOTH WHITENING}

The most convenient, cost-effective teeth whitening treatment you can recommend to patients is Professional Whitening Strips from WhiteWash Laboratories.

The mouldable plastic strips come with the optimum amount of whitening gel to simply, safely and effectively whiten your patients' teeth. They come in two strengths: a $4 \%$ variety for low sensitivity and a premium $6 \%$ strength.

Professional Whitening Strips are great as a practice builder and offering the treatment will attract new patients.

You can also recommend the Sonic Whitening Toothbrush, the Nano-Silver Toothbrush, and the Professional Whitening Toothpaste with Silver Particle Technology. All are specially designed to help keep your patients' teeth sparkling.

Introduce the benefits of WhiteWash Laboratories to your practice today. Call 08446869150 or visit www.whitewashlaboratories.com. 